\title{
Eastward sub-auroral ion drifts or ASAID
}

\author{
M. Voiculescu ${ }^{1}$ and M. Roth ${ }^{2}$ \\ ${ }^{1}$ Department of Physics, Faculty of Sciences, University "Dunărea de Jos" Galati, Romania \\ ${ }^{2}$ Belgian Institute for Space Aeronomy, Brussels, Belgium
}

Received: 7 February 2008 - Revised: 23 May 2008 - Accepted: 5 June 2008 - Published: 18 July 2008

\begin{abstract}
From satellite data sampling the top ionosphere in the Northern Hemisphere we have identified strong eastward ion drifts, with speeds larger than $1 \mathrm{~km} / \mathrm{s}$, widths of $1^{\circ}-2^{\circ}$, occurring at similar temporal and spatial locations as rapid westward ion drifts known as sub-auroral ion drifts (SAID). We have called these events "abnormal sub-auroral ion drifts" (ASAID). Two events observed in the 20:0022:00 MLT interval are discussed: the first occurring on 21 September 2003 and the other on 12 October 2003. Tomographic reconstructions of the electron density in the Fregion, based on satellite data, provided by the Scandinavian tomography chain, were also available. We have observed that ASAID are accompanied by upward flows with a speed of the same order as that of the zonal ion drift. They coincide with deep, narrow troughs in the total ion density, both at the altitude of the F15 DMSP satellite $(850 \mathrm{~km})$ and in the F-region of the ionosphere, but do not seem to be a feature of the convective transport. During the entire duration of ASAID the electron temperature is very high while, contrary to SAID, the ion temperature has no clear variation. Both events described in this paper end up turning into classical SAID. Satellite data indicate that the generator of ASAID could be located inside the plasmasphere close to the plasmapause and we suggest a possible mechanism for their formation.
\end{abstract}

Keywords. Ionosphere (Ionospheric disturbances; Plasma temperature and density)

\section{Introduction}

One example of the coupling of the magnetosphereionosphere system is the polarization jet (PJ), discovered by Galperin et al. (1974) and usually referred to as sub-auroral

Correspondence to: $\mathrm{M}$. Voiculescu

(mirela.voiculescu@ugal.ro) ion drift (SAID) (Spiro et al., 1979; Anderson et al., 1993). They are strong westward ion flows observed in the F-region and topside ionosphere, with velocities larger than $1 \mathrm{~km} \mathrm{~s}^{-1}$, occurring at sub-auroral latitudes (i.e. equatorward of the nightside auroral zone) at about $50-65^{\circ}$ geomagnetic latitude (Anderson et al., 1993; Karlsson et al., 1998). They have a narrow latitudinal extent $\left(1^{\circ}-2^{\circ}\right)$ and last $30 \mathrm{~min}$ to $3 \mathrm{~h}(\mathrm{An}$ derson et al., 1993, 2001). SAIDs are considered to be a type of sub-auroral polarization streams (SAPS), i.e. broad westward plasma flow whose width is not necessarily narrow (Foster and Burke, 2002; Foster and Vo, 2002; Yeh et al., 1991).

Satellite observations and modelling results show that during SAID the ion temperature is high in the F-region, due to collisions between drifting ions and neutral atoms while, for most of the cases, the electron temperature is unchanged (Moffett et al., 1998; Anderson et al., 1993). Sometimes the electron temperature is also increased at F-region heights (Moffett et al., 1998). SAID events occur mainly in the 18:00-24:00 MLT sector and are associated with strong poleward-directed electric fields. Around $85 \%$ of them are accompanied by ionospheric density troughs (Anderson et al., 2001). They are observed during the substorm recovery phase, although not all SAIDs are related to a substorm (Anderson et al., 1993; Karlsson et al., 1998; Anderson et al., 2001). They are often located on the equatorward edge of the Region 2 current (Anderson et al., 2001; Foster and Vo, 2002). De Keyser (1999) computed that for typical values of the height-integrated Pedersen conductivity $(0.3 \mathrm{~S})$, ionospheric electric potential difference $(20 \mathrm{kV})$ and latitudinal width of the SAID $\left(0.5^{\circ}\right)$ at the altitude of $400 \mathrm{~km}$, the height-integrated current along the latitude-aligned drift band is $0.05 \mathrm{~A} \mathrm{~m}^{-1}$ (see also Rich et al., 1980). In some cases the westward ion flow is accompanied by a vertical upward flow (Anderson et al., 1991).

Three theories try to explain the initiation and development of SAID as the result of magnetospheric processes:

Published by Copernicus Publications on behalf of the European Geosciences Union. 
1. The magnetospheric current generator theory (Anderson et al., 1993; Karlsson et al., 1998) assumes that during substorms strong downward FAC (R2 currents) close with upward FAC (R1 currents) via poleward horizontal Pedersen currents. Due to the low ionospheric conductivity in the night sub-auroral region, a high poleward electric field is set up, which leads to fast westward ion drifts. Due to frictional heating and/or to upward flow the ionospheric density decreases. The ionospheric conductance decreases, so that a feedback mechanism acts to further increase the electric field.

2. The magnetospheric voltage generator mechanism introduced by Southwood and Wolf (1978), based on tracing the drift paths of individual charged particles in the magnetospheric electric field, predicts an energydependent evolution of the "injection boundary" (McIlwain, 1974) because of the dispersion of ions and electrons of different temperatures. This leads to the formation of a space-charge layer (Alfvén layer), which carries shielding currents because of the non-zero ionospheric conductivity. During a plasma injection, ions penetrate closer to the Earth than electrons (in the equatorial plane), generating a charge separation electric field that maps into the high-latitude ionosphere as a poleward electric field. When the substorm progresses the thickness of the space-charge layer decreases and the charge-separation electric field increases. This results in a fast westward ion drift in the ionosphere. From this point forward the scenario resembles the previous one. However, because the Alfvén layer thickness is of the order of $1 R_{E}$, the space-charge layer remains, therefore, relatively thick, making it hard to explain the narrow latitudinal extent of SAID layers.

3. The third mechanism (Lemaire et al., 1997; De Keyser et al., 1998; De Keyser, 1999, 2000) explains SAID as the result of a different type of magnetospheric voltage generator. The physical mechanism focuses on the microphysics of an inward moving injected plasma front. The finite gyroradius effects at this front interface are responsible for creating fine-scale structure, which allows one to interpret the narrow SAID as the ionospheric signature of such a magnetospheric interface between cold plasma trough and hot injected particles. The azimuthal shear flow between the injected plasma and the partially corotating plasmatrough in the vicinity of the plasmapause, together with the thermoelectric effects at the interface, are responsible for the generation of intense electric fields in the premidnight sector, where SAID events are observed.

In the present paper we focus on what we think to be a new kind of ionospheric plasma flow: strong $\boldsymbol{E} \times \boldsymbol{B}$ eastward ion drifts. During several days of September and October 2003 the DMSP F15 satellite measured several ion drifts, with speeds larger than $1 \mathrm{~km} / \mathrm{s}$, widths of 1-2 degrees and occurring at similar temporal and spatial locations as "normal" SAID (i.e. in the pre-midnight sector and at sub-auroral latitudes) but flowing eastward. Such flows are intriguing since none of the SAID theories predicts the possibility of an eastward ion drift and/or of an equatorward orientation of the associated electric field. For obvious reasons we have called them ASAID - Abnormal Subauroral Ion Drifts. They are rare (a search of several months before and after the period when the ASAIDs were observed showed nothing similar), but the analysis of their characteristics might help in identifying the most probable mechanism at work when a SAID or a SAPS is observed.

\section{Observations}

Our analysis is based on DMSP data (F15) providing horizontal and vertical ion drifts, plasma density, ion and electron temperatures, magnetic variations, electron and ion precipitation in the form of downward differential energy fluxes. The F15 spacecraft has a polar sun-synchronous orbit (fixed in local time), sampling the upper ionospheric plasma at about $840 \mathrm{~km}$ in an approximately 21:30-09:30 local time orientation. Its orbital period is $101 \mathrm{~min}$. The spacecraft collects data across a $3000-\mathrm{km}$ swath, providing global coverage of the Earth twice per day (e.g. Drayton et al., 2005). The ion drift meter (IDM) instrument is known to produce poor results when the density is below approximately $1 \times 10^{3} \mathrm{~cm}^{-3}$ (F. J. Rich, personal communication). In the events discussed in the present paper, an ion density as low as the mentioned level has never been reached. Caution must be also paid when the ion density is below $3 \times 10^{3} \mathrm{~cm}^{-3}$ (F. J. Rich, personal communication), but in such cases the instruments produce usable data as long as the ion composition is essentially $\mathrm{O}^{+}$ions (http://cindispace.utdallas.edu/DMSP/quality.htm). When the percentage of $\mathrm{H}^{+}$or $\mathrm{He}^{+}$in the plasma increases above $15 \%$, the IDM is compromised and the data are not reliable (Drayton et al., 2005). We have checked the reliability of the F15 data similarly to the method used in Drayton et al. (2005). Each 4-s averaged data point is assigned a quality tag of 1 (measurement is reliable), 2 (measurement is questionable, use with caution), 3 (measurement is poor), or 4 (measurement quality is undetermined). Therefore we checked the ion percentage, removed those points corresponding to measurements when the percentage of light ions was too high, and used only ion data for which the oxygen ions percentage was high enough to give reliable results (i.e. quality tag 1) . Regarding the problem of photoelectrons, we have chosen only F15 data which, at the time of the selected events, were on the dusk-premidnight sector. Therefore the effect of photoelectrons should not be important.

In order to assess the possible effect of the Interplanetary Magnetic Field (IMF) and of the convective transport of ionospheric plasma on the ASAID, we have also used 


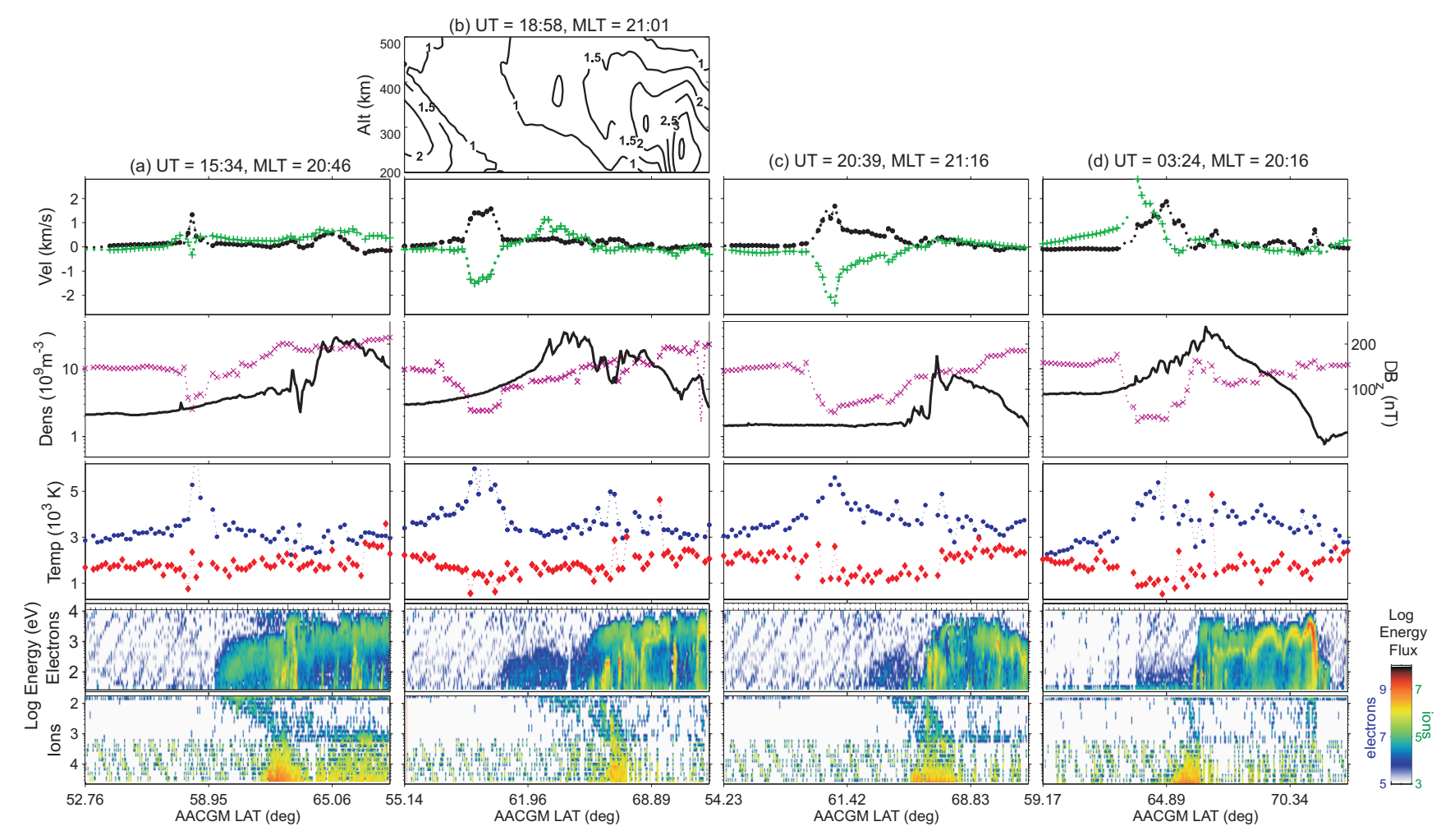

Fig. 1. The case of 21 September 2003. Each vertical set of panels (a-d) corresponds to a 5-min time interval from selected DMSP crossings when an ASAID (and, at the end, a SAID) was observed. A single plot has been added on top of panel (b) to show the results of a tomographic reconstruction of the electron density in the F-region, corresponding to the MLat where the ASAID was observed. UT and MLT of the beginning of each interval are placed on top of each vertical panel (for instance, in panel (a), the satellite is at $52.76^{\circ} \mathrm{MLat}$ at $15: 34 \mathrm{UT}$ and 20:46 MLT). For the DMSP data, the cells of the first row illustrate the profiles of the transversal and vertical ion drift velocity (green crosses: horizontal ion drift with positive values in the westward direction; black circles: vertical ion drift, positive values upward). The second row illustrates the profiles of the ion density (magenta " $x$ " symbols) and of the magnetic deviation in the east-west direction (black curve). The third row illustrates the temperature profiles (blue asterisks: electron temperature; red diamonds: ion temperature). Markers show good data points. Finally, the last two rows display the electron (top) and ion (bottom) differential energy fluxes.

IMF measurements in the solar wind, provided by the ACE spacecraft, to model the convection pattern by means of the Weimer convection model (Weimer, 1995).

We have restricted our investigations to the Northern Hemisphere because, for these events, observations of ionospheric electron density in the F-region by satellite tomography means were available (for details about the tomographic chain and tomographic images of the ionosphere used here, see Nygrén et al., 1996, and Voiculescu et al., 2006). The tomographic chain scans the ionosphere at a geographical longitude $20^{\circ} \mathrm{E}$ and has a geographical latitudinal coverage from about $55^{\circ} \mathrm{N}$ to $75^{\circ} \mathrm{N}$. Coincident DMSP passes are expected in an interval of 2-3 h centered at 18:00 UT.

The eastward drifts were observed on several days between 18 and 25 September 2003, at latitudes of $57^{\circ}-60^{\circ}$ MLat and during the $9-12$ October 2003 period around $65^{\circ}$ MLat. Unless otherwise explicitly stated, in this paper the latitude and longitude are Altitude Adjusted Corrected GeoMagnetic coordinates and are abbreviated as "MLat" for latitude and "MLong" for longitude.
In the following we will concentrate only on two events: the first one occurring on 21 September 2003 and the second one on 12 October 2003. By "event" we mean the entire interval during which a rapid eastward drift was seen in satellite data, starting with the time of the satellite pass when a spike was observed first and ending with the time of the last pass when the ASAID was still seen in the velocity data. The ASAIDs were observed in the 20:00-22:00 MLT interval, when F15 passes over the Northern Hemisphere at local evening-night time.

\subsection{The case of 21 September 2003}

On 21 September 2003 (Fig. 1) an eastward spike in the horizontal velocity was seen first at 15:34 UT. The drift was observed during five successive passes among which we have selected three examples, shown in panels $(\mathrm{a}-\mathrm{c})$ of Fig. 1.

This event seems to start around 13:30 UT (plot not shown in Fig. 1), when F15 observed a local reduction in the westward ion velocity, at $58^{\circ}$ MLat, $71^{\circ}$ MLong. The westward 
ion velocity decreases from about $700 \mathrm{~m} / \mathrm{s}$ at $56^{\circ}$ MLat to 25 $\mathrm{m} / \mathrm{s}$ at $57.5^{\circ}$ MLat and increases to $1000 \mathrm{~m} / \mathrm{s}$ at $58.5^{\circ}$ MLat. A fast upward ion flow and a reduction in the ion density are observed at the same location.

After 90 min, i.e. at the time of the next DMSP pass, the top cell of panel (a) shows that, at that particular location, the ion velocity (green crosses) turns eastward while the background flow remains westward. The velocity of the upward flow, represented by black circles in same panel, is also high. Both ion drifts are localized, spanning about $0.5^{\circ}-2^{\circ}$ in latitude. The eastward ion velocity increases rapidly with time, so that at 17:16 UT an eastward jet is observed in the ion velocity field at $58^{\circ}$ MLat, with velocities reaching more than $2000 \mathrm{~m} / \mathrm{s}$ (plot not shown). The eastward ion drift is seen during the following four passes, among which two of them are shown in the top cells of panels (b) and (c) in Fig. 1. The ASAID event lasts for about (at least) $5 \mathrm{~h}$. The velocity varies slightly but remains high until at least 23:00 UT, the time of the last DMSP pass when the high eastward ion velocitiy is seen in the sub-auroral region. The evolution of ASAID suggests that there is an anticorrelation between the latitudinal width and the peak velocity. This is similar to what Figueirido et al. (2004) observed for SAIDs. Around 01:30 UT the drift turns westward, so that at 03:40 UT (top cell of panel (d) in Fig. 1) the ASAID turns into a classic SAID - a westward ion drift with similarly high velocities. The upward ion flow is still observed when the zonal jet changes toward west but its peak is no longer coincident with the zonal one but is located at about $1^{\circ}$ north.

The other parameters also vary at the location of the ASAID (see second and third rows in Fig. 1). An ion density trough at $850 \mathrm{~km}$, whose width is almost the same as the width of the ion jet, is seen in satellite data during the entire period. Images of the electron density in the F-region are displayed in the form of altitude-latitude plots in a magnetic meridional plane at about $104^{\circ}$ MLong. The electron density in the F-region is obtained by means of satellite tomography from the Finnish chain receivers (Nygrén et al., 1996). The latitudinal extent of the reconstructed electron density is about $15^{\circ}$, between $57^{\circ}$ and $72^{\circ}$ MLat. The F15 DMSP satel-

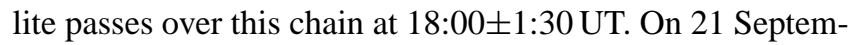
ber 2003 there was a tomographic reconstruction of the Fregion at 18:35 UT (shown at the top of panel (b) in Fig. 1), i.e. close to the time when the eastward spike is seen in the DMSP measurements, namely 18:59 UT. A density trough, centered at $58^{\circ}$ MLat, is seen in the F-region, whose walls are almost aligned with the edges of the ASAID. This means that the trough observed at the topside ionosphere extends down to F-region altitudes.

In the tomographic reconstructions of the F-region at earlier times a narrow trough is seen between about $60^{\circ}$ and $61^{\circ}$ MLat, starting at 14:58 UT, i.e. 17:30 MLT. Another DMSP satellite, F13, whose orbit crosses the northern auroral region at about the same time shows that the zonal velocity at this MLT is westward and small. Model re- sults show that the F-region trough extends longitudinally towards 21:00 MLT (Schunk, 1988; Quegan, 1989), which indicates that the trough might have preceded the eastward jet. Since no other coincident measurements of the ionosphere are available for this event, it is difficult to draw any conclusion about the cause-effect relationship between the ASAID and the F-region trough.

During the event the $B_{z}$ component of the IMF was most of the time southwards. Towards the end of the ASAID event $B_{z}$ turned northwards. The IMF $B_{y}$ component was mostly negative but changed to positive values some time earlier, when the ASAID was still observed. Convection models based on IMF data (Weimer, 1995) show that the ASAID is observed close to the edge of the dusk cell, where the convective flow is slow and westward. This is supported by the velocity profile provided by DMSP data. Poleward of the ASAID the velocities are westward and have values up to $700-1000 \mathrm{~m} / \mathrm{s}$. The geomagnetic activity is medium, with $K_{p}$ decreasing from 4 to 3 during the event. The $\mathrm{AL}$ index decreases to -1000 around 12:00 UT, a short time before the ASAID was observed, and recovers towards 18:00 UT. The AU index is small, which, together with the AL variation, indicates a substorm activity, according to Burke et al. (2006).

The electron temperature is extremely high, reaching more than $6000 \mathrm{~K}$, during the ASAID duration. At 15:34 UT (panel (a) of Fig. 1), when the eastward drift is still small but the upward ion flow is high, the ion temperature has a slight increase at the point where the eastward turning of the velocity is observed. During the following passes there is no clear ion temperature variation. Satellite data from previous passes show that the electron temperature had nearly the same value before the ASAID started to develop.

Spectrogram data from DMSP show that the maximum of the ASAID velocity occurs in regions void of precipitation, around $2^{\circ}-4^{\circ}$ south of ble, the zero-energy boundary of the electron precipitation, which coincides with $b 1 i$, the zero-energy boundary of the equatorward ion precipitation, both identified automatically using the criteria of Newell et al. (1996). The automatic identification of boundaries also identifies $b 0$, which is the latitude at which precipitation above which noise level is observed (often but not necessarily $b 0 \approx b 1 e \approx b 1 i$ ) and that would correspond to the farthest closed magnetic field lines. When ble and bli are very close, this boundary could be identified as the footprint of the plasmapause (Newell et al., 1996). This suggests that the magnetic footprint of the ASAID event in the equatorial plane is located somewhere inside the plasmasphere, close to its edge. The existence of a dispersive signature, the spread in energy, the coincidence with electron precipitation suggest that the source of the precipitation is the plasma sheet (Newell et al., 1996; Kauristie et al., 1999; Hultqvist, 2002). Towards the end of the event (starting around 22:20 UT) the boundary of ion precipitation starts to move equatorward, so that when the ASAID ends and turns into a SAID (at 01:40 UT), the ion precipitation is almost completely south 


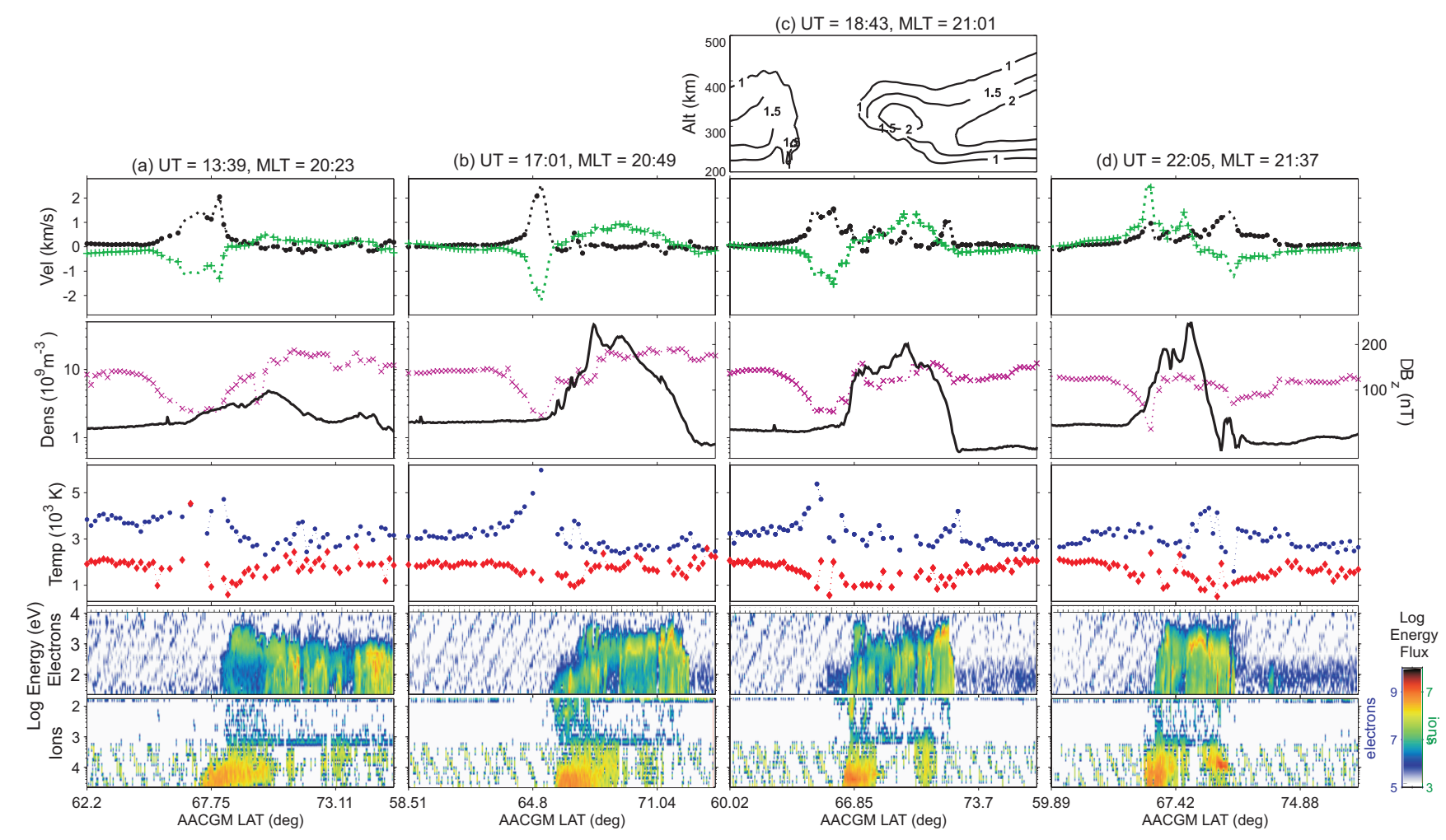

Fig. 2. The case of 12 October 2003. See caption of Fig. 1 for details. Note that, in this figure, the reconstructed F-region density is on top of the third vertical panel.

of the zero-energy boundary of the electron precipitation. Strong electron acceleration events are also observed at this time.

Magnetometer data show that most of the time the latitudinal variation of the magnetic field east-west deviation is either zero or small and positive, which, in the thin sheet approximation (e.g. Anderson et al., 2001), indicates that the ASAID is observed in regions with zero or very small downward current. On the other hand, an oscillating significant downward current is observed when the zonal jet turns westward (Fig. 1, panel d), as is the case for many SAID observations (e.g. Anderson et al., 2001).

There is no similar observation in the Southern Hemisphere, suggesting either that the source is local, or that the ionospheric conditions play a role, as is also the case for many SAID events (Anderson et al., 2001; Figueirido et al., 2004). One such condition could be an ionospheric trough, whose location and characteristics are different in the two hemispheres, due to the different offset between geographical and geomagnetic axes (Horwath and Essex, 2003).

\subsection{The case of 12 October 2003}

On 12 October 2003 (Fig. 2) an eastward drift of about $1000 \mathrm{~m} / \mathrm{s}$ was first measured at 13:40 UT at $67^{\circ}$ MLat (Fig. 2, panel (a), top cell, green crosses). Unlike the case of 21
September 2003, this event starts abruptly. There is no previous perturbation of the background westward convection flow and the other parameters, namely the temperatures, density and velocity do not show any particular behavior during previous passes. The DMSP F15 satellite observed the ASAID during each pass until 20:24 UT, when it ends by suddenly reversing its direction and turning into a westward SAID (whose speed is more than $2000 \mathrm{~m} / \mathrm{s}$ - panel d), as in the case of 21 September 2003. The eastward drift is accompanied by an equally fast upward ion flow (black dots), which is significantly reduced when the horizontal flow is westward. The jet is narrow, with widths between $1^{\circ}$ and $2^{\circ}$.

The ASAID coincides with a density trough in the topside ionosphere. A well-defined trough is seen in tomographic reconstruction of the F-region at 18:47 UT (the single plot added at the top of panel $\mathrm{c}$ in Fig. 2), very close to 18:44 UT, when the DMSP F15 satellite observes the ASAID. The alignment of the trough with the ASAID and with the density depletion observed in the topside ionosphere is better than in the case of 21 September 2003. Previous tomographic images of the F-region show that a shallow trough was present at 15:12 UT $(\approx 17: 25 \mathrm{MLT})$ between $69^{\circ}$ and $71^{\circ}$ MLat. This trough is north of the location where the ASAID and the associated upper ionospheric trough are observed at the same UT by the F15 satellite, $45^{\circ}$ eastwards (i.e. at 20:45 MLT). Therefore it is difficult to say whether the evening F-region 
trough seen in Fig. 2 is the extension of the afternoon trough, preceding the ASAID. However, we note that, in the tomographic reconstructions, the F-region trough is seen at the same latitude until at least 21:08 UT $(\approx 23: 45$ MLT $)$. This is unexpected, since it is well-known that, in the pre-midnight sector, the F-region trough moves to lower magnetic latitudes with time (Rodger et al., 1992; Voiculescu et al., 2006). We infer that the ionospheric trough, extended from 300 to $850 \mathrm{~km}$, is linked to the ASAID.

The latitudinal profiles of the density (Fig. 2, second row, magenta " $x$ " symbols) and temperatures (third row) at the altitude of $845 \mathrm{~km}$ show the same variations as in the case of 21 September. Except for the first plot at 13:40 UT, panels (b) and (c) display a significant increase in the electron temperature and no clear variation of the ion temperature. The electron temperature drops in the end of the event, so that during the SAID its value is normal (Fig. 2, panel d). The ion temperature is slightly higher at the SAID location, as expected at the altitude of $850 \mathrm{~km}$ (e.g. Moffett et al., 1998).

During the first $3 \mathrm{~h}$ the ASAID has a slow movement equatorwards, reaching $64^{\circ}$ MLat at 17:00 UT, followed by a poleward retreat to the original location during the next hour. The geomagnetic activity is low, with $K_{p}$ around 1. A negative excursion in AL of $-200 \mathrm{nT}$ was recorded between 10:00 and 12:00 UT, right before the ASAID was observed the first time. The equatorward movement took place sometime before 17:00 UT, and around 16:00 UT a second brief excursion was observed in the AL index. Although both variations are small, they could account for the small displacement of the ASAID towards the equator.

The interplanetary background is also quiet. During the event the z-component of the IMF was negative and small (with some brief turnings). The y-component of the IMF was also small and varying, except during the last couple of hours when it increased to positive values of $4 \mathrm{nT}$. For such IMF conditions, ionospheric plasma convection is slow and confined to high latitudes (Weimer, 1995). The ASAID is thus located, as in the previous case, at the border of the convection cell, where the convection velocity should be, according to the Weimer modeled pattern, westwards and extremely slow (if convecting at all). This is confirmed also by DMSP velocity data that reveal a smoothly varying westward velocity poleward of the ASAID. It should be mentioned that ACE data show a sudden increase in the solar wind pressure, a decrease in the IMF magnitude, and a relatively small variation of the solar wind velocity at 11:20 UT. The resulting solar wind impulse should be felt at the magnetosphere around 12:30 UT, i.e. shortly before the ASAID was observed the first time by DMSP.

The particle precipitation (bottom rows), mirroring the state of the inner magnetosphere, has other characteristics than for the 21 September 2003 event. The poleward edge of the ASAID is colocated with the zero-energy electron boundary (ble) and the maximum eastward velocity coincides or is very close to the ion precipitation boundary. The ion precip- itation is clustered in a relatively narrow band of high energy and takes place at lower latitudes than the electron precipitation. The dispersive signature of the ions is weaker or absent. The automatic identification of boundaries, places $b 2 i$ (the point where the energy flux of ions above $3 \mathrm{keV}$ has a maximum) at lower latitudes than ble (the zero-energy electron precipitation boundary) and $b l i$ (the zero-energy ion precipitation boundary), which suggests that the source of ion precipitation is the ring current or an injection of high energy plasma (Newell et al., 1996; Kauristie et al., 1999). Since the latter is associated with disturbed geomagnetic conditions and 12 October 2003 is a very quiet day, we infer that the source of the ion precipitation is the ring current.

When the zonal flow turns westward the structure of precipitation also changes (panel d). It reveals a strong and latitudinally extended electron acceleration process poleward of the SAID, while two sheets of downcoming energetic ions are seen on each side of the electron acceleration region, the equatorward one being coincident with the SAID (see spectrograms in the last cell of panel d). We assume that the zonal ion drift changed its direction when energetic electrons of the plasma sheet came close enough to the ion sheet to generate the poleward electric field associated to SAID.

Magnetometer data indicate that ASAID does not coincide with a parallel current sheet. A downward current develops at the poleward part of the ASAID at 18:43 UT and extends gradually to lower latitudes. When the ASAID turns into SAID the zonal drift is embedded in a downward current sheet of approximately $0.5 \mu \mathrm{A} / \mathrm{m}^{2}$, calculated from the variations of magnetic field deviations, as it is the case with most SAIDs (e.g. Anderson et al., 2001).

A weaker and more irregular eastward drift, together with a lower upward ion drift (both of $\approx 1000 \mathrm{~m} / \mathrm{s}$ ) are observed in the Southern Hemisphere at about $68^{\circ}$ MLat, at 13:05 UT (22:36 MLT), shortly after the solar wind impulse mentioned above reached the magnetopause and right before the first observation of the ASAID in the Northern Hemisphere. An upward flow, but no eastward drift, is observed in the following southern passes.

\section{Discussion and conclusions}

The rapid eastward sub-auroral ion drifts have similar characteristics:

1. The ASAID events were observed at sub-auroral latitudes between 20:00 and 21:30 MLT. They were not encountered in other intervals where DMSP coverage was available, i.e. in intervals centered at 18:00 MLT or on the dawnside, around 06:00 and 09:00 MLT.

2. The ASAID events are accompanied by upward flows with equally high velocities. The upward flows diminish when the zonal flow turns westward. 
3. The ASAID events coincide with deep, narrow troughs in the total ion density, both at $850 \mathrm{~km}$ altitude and in the F-region.

4. Modeled convection patterns based on IMF values show that the location of ASAID is very close to the equatorward edge of the dusk convection cell, at latitudes where the plasma convection is low or dominated by corotation. This is confirmed by the latitudinal profiles of the zonal velocities measured by DMSP satellites. In other words, ASAID does not seem to be a feature of the convective transport.

5. The electron temperature is very high during the entire duration of the ASAID, while the ion temperature has no clear variation. In the case of 21 September 2003 a high electron temperature was observed before the event started to develop, with values close to the those observed during ASAID.

6. Both events end up by turning into a classical SAID, i.e. the direction of the zonal ion velocity reverses, reaching rapidly high values in the westward direction.

7. In both cases the ASAID was preceded by AL variations, which indicates that ASAID could be linked to (weak) substorm activity.

A possible explanation for the eastward flow is not at all straightforward. None of the theories that explain the formation of SAID predicts the occurrence of eastward sub-auroral ion drifts in the premidnight sector (or of equatorward electric fields), where the convection is generally westward. The upward ion flow could be explained as a consequence of temperature gradients induced by frictional heating of ions at lower altitudes, from where, unfortunately, observational data are not available.

It is generally accepted that high electron temperatures in the topside ionosphere are the result of downward transport of heat generated inside the inner magnetosphere due to Coulomb collisions between ring current ions and plasmaspheric particles (Mishin and Burke, 2005; Wang et al., 2006). According to Wang et al. (2006) and Prölss (2006) the equatorward edge of the electron temperature gradient indicates the location of the equatorward edge of the ring current. Elevated electron temperatures at sub-auroral latitudes might also occur on field lines linked to the equatorward edge of a steep density gradient inside the plasmasphere (Green et al., 1986). Another hypothesis is that a high sub-auroral electron temperature is an indicator of the location of the plasmapause (Brace et al., 1988).

Since we have no information about the F-region for all DMSP passes, it is impossible to establish the cause-effect relationship between the ASAID and the trough. Different explanations could be suggested:
1. the ionospheric trough is the result of ASAID, similarly to the trough generated by SAID (Anderson et al., 1993, 2001). The elevated electron temperature could cause the vibrational excitation of molecular nitrogen which could deepen the F-region trough by increasing the ion loss rate more effectively than both frictional heating and molecular expansion (Moffett et al., 1998; Vlasov and Kelley, 2003);

2. the trough is a direct consequence of the same processes that contribute to the formation of the eastward jet.

The main difference between the two types of ASAID described in this paper is the structure of the precipitation regions and the location of the ion drift relative to the precipitation boundaries, described in the previous section. During the 12 October 2003 event (Fig. 2) ion precipitation originates probably in the ring current and the ASAID is located very close to the outer edge of the plasmasphere but inside. This would mean that the plasmasphere extends to 6-7 $R_{E}$, which is not surprising because both $y$ and $z$ components of the IMF are small and in such cases the plasmasphere could extend to more than $7 R_{E}$ (Denton et al., 2004). The 21 September 2003 event occurs at much lower latitudes but one should keep in mind that the geomagnetic activity is higher and the interplanetary conditions are no longer quiet. The ion precipitation is weaker than in the case of the $12 \mathrm{Oc}$ tober 2003 and the ASAID is $1-4^{\circ}$ equatorward from both the zero-energy electron and ion precipitation boundaries. The precipitation structure is similar to what is observed for SAID by Anderson et al. (2001). This is intriguing because none of the SAID theories predicts a possibility that the electric field at the equatorial plane is oriented earthward, i.e. equatorward in the ionosphere.

The location of ASAIDs relative to the precipitation regions in both cases, as well as the high electron temperature associated with ASAIDs, suggest that these events are magnetically connected with a generator located very close to the plasmapause. Both ASAID events described in this paper are observed equatorward of the ionospheric mapping of the plasmapause. The theories and observations describing the possible formation mechanisms of SAIDs assume that the generator is outside the plasmasphere (Anderson et al., 1993; Karlsson et al., 1998; Southwood and Wolf, 1978; Lemaire et al., 1997; De Keyser et al., 1998) or located at the plasmapause (Puhl-Quinn et al., 2007).

Although there are some differences, especially in the precipitation structure, the existence of similar characteristics, i.e. high electron temperatures, upward flow, ionospheric troughs, no significant current, suggests that the explanation could be the same for both events. We propose the following scenario to explain the formation of the observed eastward drifts, associated with an equatorward electric field. The mechanism that we propose is the counterpart of that proposed by Lemaire et al. (1997) and De Keyser et al. (1998) 
for the formation of SAIDs. In the case of ASAIDs an earthward field developing in the equatorial plane is required, and this might be generated by finite gyroradius effects at the interface between the hot ring current and the cold plasmatrough. This mechanism requires a particular configuration of the inner magnetosphere and this could be the reason for which ASAIDs are not frequently observed. Hot ring current particles overlap with the plasmasphere, so that the outer edge of the ring current coincides with the plasmapause. The hot ions from the ring current create an excess positive charge in the plasma trough because of their larger Larmor radius and leave a deficit of negative charges inside the ring current region. Since the ring current is closer to the Earth than the cold neighbouring plasma trough, an earthward polarisation electric field builds up. Note that at the other interface, between the ring current and the dense plasmasphere, a significant electric field created by charge separation is unlikely, since the high density of plasmaspheric electrons act to maintain the charge neutrality.

When the present paper was in the review stage, Ebihara et al. (2008) reported that an antisunward flow was observed in SuperDARN radar data at sub-auroral magnetic latitudes in the afternoon-evening MLT sector. An antisunward flow in the evening sector means an eastward flow, similar to what we have reported in the present paper. Like "our" ASAIDs, the event observed by Ebihara et al. (2008) is located equatorward of the inner edge of plasma sheet electron precipitation. They attribute these events to a coupling between ring current and ionosphere, associated to an overshielding condition.

In this paper we aimed only at signaling, for the first time, the existence of ASAIDs and at describing some first observational characteristics. Based on observations we suggest a possible mechanism that is capable of producing strong equatorward electric fields that generate strong eastward ion drifts at ionospheric heights. However, this is only a tentative explanation and both a detailed analysis of an extended data set, as well as observational data from the inner magnetosphere are necessary for a better understanding of this new phenomenon.

Acknowledgements. The authors thank J. De Keyser, M. Echim, J. Lemaire and F. Rich for stimulating discussions and comments, as well as E. Rigo for bibliographical assistance. The work of M. Voiculescu at the Belgian Institute for Space Aeronomy was supported by a research fellowship of the Belgian Federal Science Policy Office. Project No. 81-009 of the Romanian National Plan for Research, Development and Innovation is acknowledged. The DMSP particle detectors were designed by Dave Hardy of AFRL, and data obtained from JHU/APL. We thank D. Hardy, F. Rich, and P. Newell for its use. We gratefully acknowledge the Center for Space Sciences at the University of Texas at Dallas and the US Air Force for providing the DMSP thermal plasma data and F. Rich for providing magnetometer data. The Scandinavian tomography chain is run by Sodankylä Geophysical Observatory, Finland. We are grateful to T. Raita and J. Manninen for their continuous effort in maintaining the receiver chain and for providing tomographic data and to M. Lehtinen, M. Markkanen and late J. Pirttilä for their efforts in developing the tomographic inversion routine.

Topical Editor M. Pinnock thanks S. Liléo and T. Karlsson for their help in evaluating this paper.

\section{References}

Anderson, P. C., Hanson, W. B., and Heelis, R. A.: The ionospheric signatures of rapid subauroral ion dirfts, J. Geophys. Res., 98(96), 5785-5792, 1991.

Anderson, P., Hanson, W., Heelis, R., Graven, J., Baker, D., and Frank, L.: A proposed production model of rapid subauroral ion drfits and their relationship to substrom evolution, J. Geophys. Res., 98, 6069-6078, 1993.

Anderson, P. C., Carpenter, D. L., Tsuruda, K., Mukai, T., and Rich, F. J.: Multisatellite observations of rapid subauoral ion drifts (SAID), J. Geophys. Res., 106(A12), 29 585-29 599, 2001.

Brace, L. H., Chappell, C. R., Chandler, M. O., Comfort, R. H., Horwitz, J. L., and Hoegy, W. R.: F region electron temperature signatures of the plasmaspause based on Dynamics Explorer 1 and 2 measurements, J. Geophys. Res., 93, 1896-1908, 1988.

Burke, W. J., Huang, C. Y., and Rich, F. J.: Energetics of April 2000 magnetic superstorm observed by DMSP, Adv. Space Res., 38, 239-252, 2006.

De Keyser, J.: Formation and evolution of subauroral ion drifts in the course of a substorm, J. Geophys. Res., 104, 12 339-12 349, 1999.

De Keyser, J.: Storm-time Energetic Particle Penetration Into the Inner Magnetosphere as the Electromotive Force in the Subauroral Ion Drift Current Circuit, in: Magnetospheric Current Systems, edited by: Ohtani, S., Fujii, R., Hesse, M., and Lysak, R. L., pp 261-265, AGU Monograph 118, Washington, 2000.

De Keyser, J., Roth, M., Lemaire, J.: The magnetospheric driver of subauroral ion drifts, Geophys. Res. Lett., 25(10), 1625-1628, 1998.

Denton, R. E., Menietti, J. D., Goldstein, J., Young, S. L., and Anderson, R. R.: Electron density in the magnetosphere, J. Geophys. Res., 109, A09215, doi:10.1029/2003JA010245, 2004.

Drayton, R. A., Koustov, A. V., Hairston, M. R., and Villain, J.P.: Comparison of DMSP cross-track ion drifts and SuperDARN line-of-sight velocities, Ann. Geophys., 23, 2479-2486, 2005, http://www.ann-geophys.net/23/2479/2005/.

Ebihara, Y., Nishitani, N., Kikuchi, T., Ogawa, T., Hosokawa, K., and Fok, M.-C.: Two-dimensional observations of overshielding during a magnetic storm by the Super Dual Auroral Radar Network (SuperDARN) Hokkaido radar J. Geophys. Res., 113, A01213, 1475, doi:10.1029/2007JA012641, 2008.

Figueiredo, S., Karlsson, T., and Marklund, G. T.: Investigation of subauroral ion drifts and related field-aligned currents and ionospheric Pedersen conductivity distribution, Ann. Geophys., 22, 923-934, 2004,

http://www.ann-geophys.net/22/923/2004/.

Foster, J. C. and Vo, H. B.: Average characteristics and activity dependence of the subauroral polarization stream, J. Geophys. Res., 107(A12), 1475, doi:10.1029/2002JA009409, 2002.

Foster, J. C. and Burke, W. J.: SAPS: A New Characterization for Sub-Auroral Electric Fields, EOS, 83, 393-394, 2002.

Galperin, Y., Ponomarev, Y., and Zosima, A.: Plasma convection in the polar ionosphere, Ann. Geophys., 30, 1, 1974. 
Green, J. L., Waite Jr., J. H., Chappell, C. R., Chandler, M. O., Doupnik, J. R., Richards, P. G., Heelis, R., Shawhaw, S. D., and Brace, L. H.: Observations of ionospheric magnetospheric coupling: DE and Chatanika coincidences, J. Geophys. Res., 91, 5803-5815, 1986.

Horvath, I. and Essex, E. A.: The southern-hemisphere mid-latitude day-time and night-time trough at low sunspot numbers, J. Atmos. Solar-Terr. Phys., 65, 917-940, 2003.

Hultqvist, B.: Downward ion acceleration at auroral latitudes: cause of parallel electric field, Ann. Geophys., 20, 117-1136, 2002, http://www.ann-geophys.net/20/117/2002/.

Karlsson, T., Marklund, G. T., and Blomberg, L. G.: Subauroral electric fields observed by the Freja satellite: A statistical study, J. Geophys. Res., 103(A3), 4327-4341, 1998.

Kauristie, K., Weygand, J., Pulkkinen, T. I., Murpree, J. S., and Newell, P. T.: Size of the auroral oval: UV ovals and precipiation boundaries compared, J. Geophys. Res., 104(A2), 2321-2331, 1999.

Lemaire J., Roth, M., and De Keyser, J.: High altitude electrostatic fields driving subauroral ion drifts, in: MRAT Proceedings, edited by: Lui, T., COSPAR Colloquia Series, 61-64, 1997.

McIlwain, C. E.: Substorm injection boundaries, in: Magnetospheric Physics, edited by: McCormack, B. M., pp. 143-154, D. Reidel, Norwell, Mass., 1974.

Mishin, E. W. and Burke, W. J.: Stormtime coupling of the ring current, plasmasphere, and topside ionosphere: Electromagnetic and plasma disturbances, J. Geophys. Res., 110, A07209, doi:10.1029/2005JA011021, 2005.

Moffett, R. J., Ennis, A. E., Bailey, G. J., Heelis, R. A., and Brace, L. H.: Electron temperatures during rapid subauroral ion drift events, Ann. Geophys., 16, 450-459, 2006, http://www.ann-geophys.net/16/450/2006/.

Newell, P. T., Feldstein, Y. I., Galperin, Y. I., and Meng, C.-I.: Morphology of nightside precipitation, J. Geophys. Res., 101(A5), 10737-10748, 1996.

Nygrén, T., Markkanen, M., Lehtinen, M., Tereshchenko, E. D., and Khudukon, B. Z.: Stochastic inversion in ionospheric radiotomography, Radio Sci., 32, 2359-2372, 1997.

Prölss, G. W.: The equatorward wall of the subauroral trough in the afternoon/evening sector, Ann. Geophys., 25, 645-659, 2007, http://www.ann-geophys.net/25/645/2007/.
Puhl-Quinn, P. A., Matsui, H., Mishin, E., Mouikis, C., Kistler, L., Khotyaintsev, Y., Décréau, P. M. E., and Lucek, E.: Cluster and DMSP observations of SAID electric fields, J. Geophys. Res., 112, A05219, doi:10.1029/2006JA012065, 2007.

Quegan, S.: The influence of convection on the structure of the high-latitude ionosphere, Phil. Trans. R. Soc. Lond. A, 328, 119 137, 1989.

Rich, F. J., Burke, W. J., Kelley, M. C., and Smiddy, M.: Observations of field-aligned currents in association with strong convection electric fields at subauroral latitudes, J. Geophys. Res., 85, 2335-2340, 1980.

Rodger, A. S., Moffet, R. J., and Quegan, S.: The role of ion drift in the formation of ionization troughs in the mid- and high-latitude ionosphere - a review, J. Atmos. Terr. Phys., 54(1), 1-30, 1992.

Schunk, R. W.: A Mathematical Model of the Middle and High Latitude Ionosphere, PAGEOPH, 127, 2/3, 1988.

Southwood, D. J. and Wolf, R. A.: An assessment of the role of precipitation in magnetospheric convection, J. Geophys. Res., 83 5227-5232, 1978.

Spiro, R., Heelis, R., and Hanson, W.: Rapid subauroral ion dirfts observed by Atmospheric Explorer C, Geophys. Res. Lett., 6, 657-660, 1979.

Vlasov, M. N. and Kelley, M. C.: Modeling of the electron density depletion in the storm-time trough on April 20, 1985, J. Atmos. Solar-Terr. Phys., 65, 211-217, 2003.

Voiculescu, M., Virtanen, I., Nygrén, T.: The F region ionospheric trough: seasonal dependence and relation to IMF, Ann. Geophys., 24(1), 173-185, 2006.

Voiculescu, M. and Nygrén, T.: IMF effect on ionospheric trough occurrence at equinoxes, Adv. Space Res., 40, 1935-1940, 2007.

Yeh, H.-C., Foster, J. C., Rich, F. J., and Swider, W.: Storm time electric field penetration observed at mid-latitude, J. Geophys Res., 5707-5721, 1991.

Wang, W., Burns, A. G., and Killeen, T. L.: A numerical study of the response of ionospheric electron temperature to geomagnetic activity, J. Geophys. Res., 111, A11301, doi:10.1029/2006JA011698, 2006.

Weimer, D. R.: Models of high-latitude electric potentials derived with a least error fit of spherical harmonic coefficients, J. Geophys. Res., 100, 19595-19607, 1995. 